\title{
FINITE ELEMENT MODELING AND OPERATIONAL MODAL ANALYSIS OF A HISTORICAL MASONRY MOSQUE
}

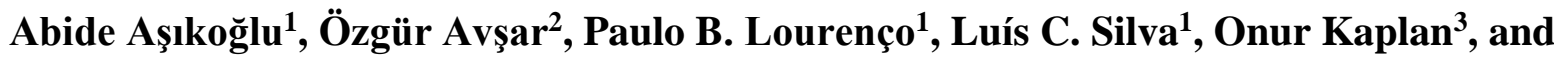 \\ Georgios Karanikoloudis ${ }^{1}$ \\ ${ }^{1}$ University of Minho, Department of Civil Engineering \\ Azurém, 4800-058 Guimarães, Portugal \\ id8027@alunos.uminho.pt, pbl@civil.uminho.pt, luisilva.civil@gmail.com, \\ karanikoloudis@hotmail.com \\ ${ }^{2,3}$ Eskişehir Technical University, ${ }^{2}$ Department of Civil Engineering \\ ${ }^{3}$ Earth and Space Sciences Institute \\ 26555 Eskişehir, Turkey \\ \{ozguravsar, onur_kaplan\}@eskisehir.edu.tr
}

\begin{abstract}
Finite Element Modeling (FEM) and Operational Modal Analysis (OMA) is herein presented for the historical masonry Kütahya Kurşunlu Mosque within the framework of its seismic performance assessment. The historical structure is located in Turkey which has a high-level seismic activity. A FEM strategy was adopted to construct a numerical model of the structure considering a simplified three-dimensional geometry and a macro-modeling approach for the masonry. A representative numerical model of the existing structure was calibrated and improved according to the OMA results obtained from ambient vibration measurements, performed in-situ. The ambient vibration measurements were operated by using two triaxial accelerometers, that one of the accelerometers was regulated as a reference station whereas the other accelerometer was relocated to seven different points on the top of the walls. Identification of the experimental modal parameters was achieved by performing two different signal processing methodologies, namely the Enhanced Frequency Domain Decomposition (EFDD) and the Stochastic Subspace Identification - Unweighted Principal Components (SSI-UPC). Results obtained from both methods were compared in terms of the Modal Assurance Criterion (MAC) which considers the mode shapes derived in a specific range of frequency. The SSI-UPC method was employed in achieving the experimental modal response of the structure and the results were compared with the eigenvalue analysis results of the preliminary numerical model. A calibration process was carried out in terms of minimizing the difference between the experimental and numerical modal response by a trial and error approach and an average error of $4.9 \%$ was calculated for the modal frequencies of the first four global modes of vibration.
\end{abstract}

Keywords: Finite Element Modeling, Operational Modal Analysis, Model Calibration, Historical Masonry Structure, Eigenvalue Analysis. 


\section{INTRODUCTION}

Architectural heritage defines the identity in communities as well as its legacy provides a particular creative quality, a uniqueness, originality, and authenticity that makes the universal value of humankind [1]. Those type of structures is facing several detrimental effects by human and environmental origin. In order to prevent the loss of architectural heritage, necessary preservation and conservation actions need to be taken. Within this sense, ICOMOS stresses that the principle of minimum intervention must be applied for the conservation of historic structures. Accordingly, the assessment of those particular structures is challenging due to their complex geometry and diverse materials. Additionally, they are usually exposed to structural changes mainly based on long-term effects, imposed damage or repair works [2, 3]. Therefore, a non-conventional approach is required in which a set of qualitative and quantitative tasks are carried out. Still, visual inspections and experimental testing can complement on constructing a precise representation of the structure. In the present paper, Kütahya Kurşunlu Mosque, which is located in Turkey, was investigated. A brief description related to the structure's location, the geometric features and the generation of the numerical model is presented. Next, the representative scheme was improved by means of the calibration process, by considering the results obtained from the experimental modal analysis.

Turkey is located in the second most seismically active zone on the Earth, namely the AlpineHimalayan Belt. The major faults are the North Anatolian Fault (NAF), the East Anatolian Fault (EAF) and the Aegean Graben, and additionally, there are several local faults throughout the country. In Figure 1, the contour distribution of Peak Ground Acceleration (PGA) is given with a $10 \%$ probability of exceedance within a period of 50 years. The red color indicates the highest seismicity nearly up to $0.8 \mathrm{~g}$ while the white color depicts the lowest seismic activity in the region and the black lines represent the faults. Accordingly, Figure 1 presents how crucial is to ensure seismic safety for historical structures. In fact, according to General Directorate of Cultural Heritage and Museums of the Republic of Turkey and the Ministry of Culture and Tourism, there are approximately 107,000 immovable cultural properties that have to be preserved, not only for seismic risk but also protected against any detrimental effects.

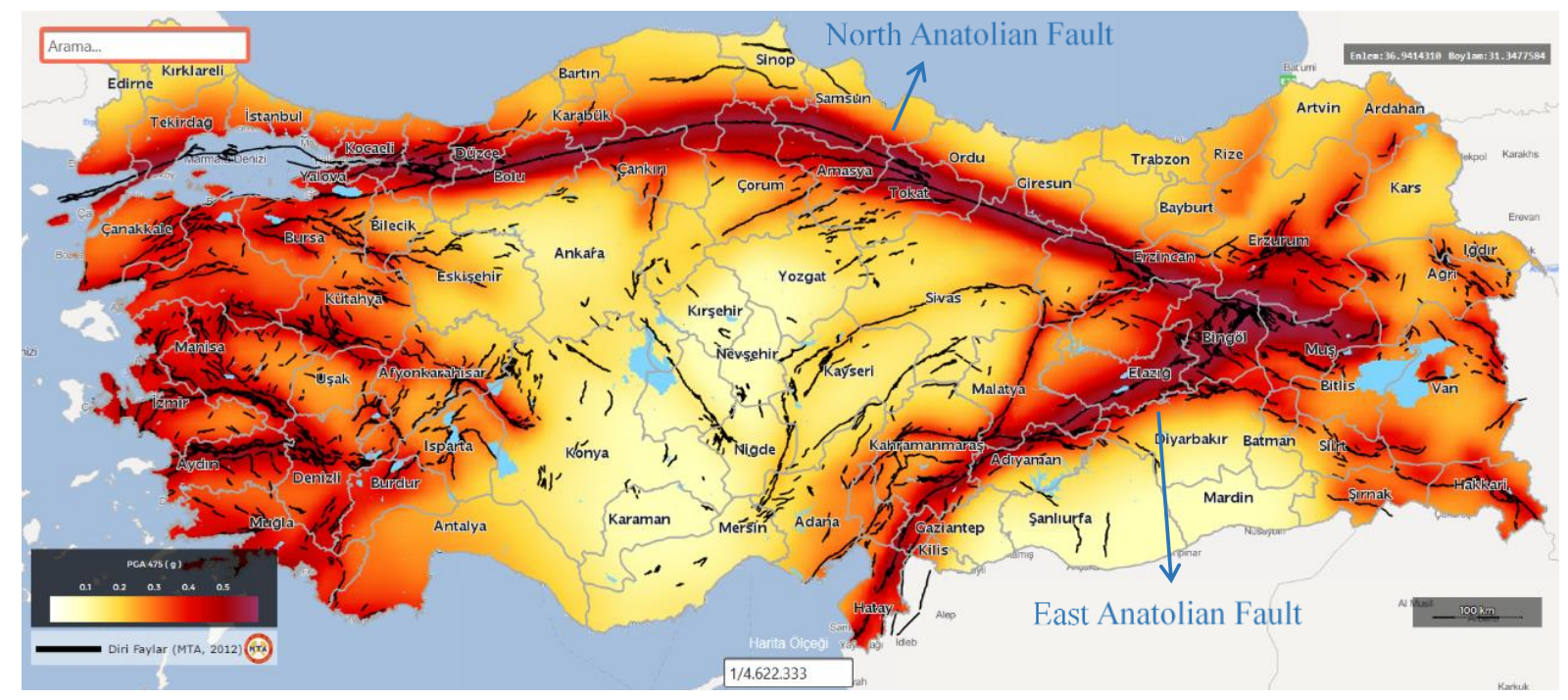

Figure 1. Seismic hazard map of Turkey [4] 
The Kütahya Kurşunlu Mosque is located in the Kütahya province with a high seismic exposition (the peak ground acceleration ranges between $0.22 \mathrm{~g}$ and $0.53 \mathrm{~g}$, [4]), which enforces the seismic assessment aiming to ensure safety for future events. The Kütahya Kurşunlu Mosque, from the $13^{\text {th }}$ century, in which, according to the restitution report prepared by the Kütahya Regional Directorate of Conversation of Cultural Assets, was constructed by using ruins of a pre-existing building in the late 1370s. It is noted that the Mosque was undergone several conservation and restoration interventions between the 13th and 19th centuries. In fact, the Directorate General of Foundations of Turkey started restoration works and seismic retrofitting interventions on the Mosque in 2013. The Kütahya Kurşunlu Mosque is located in the residential area of the city, but it is an isolated structure from its neighbor buildings. The Mosque has a rectangular plan with a length of $13.0 \mathrm{~m}$ and width of $9.3 \mathrm{~m}$ (Figure 2 and Figure 3). The minaret has a rectangular base with a polygonal transition section to a circular body, and a total height of $28.0 \mathrm{~m}$. In the main body, the load-bearing masonry walls were constructed with three-leaves, having a height of $7.8 \mathrm{~m}$, and the top point of the dome is $11.0 \mathrm{~m}$. The construction material is cut stone and brick, and the outer layer of the walls were built with cut stone; whereas rubble stone was used for the inner layer and core of the load-bearing walls. The dome, vaults, pendentives, and octagonal drum were constructed using brick. The minaret base and circular body are constituted with cut stone and brick, respectively. The seismic retrofitting was adopted by the implementation of steel girder elements, having a U160 section and placed on the top of the structural walls and the top and base parts of the drum in order to provide global structural behavior. Double row steel elements were anchored on the load-bearing walls whereas single row ones were inserted at the spaces of the drum section, where the total loss of timber elements was observed.

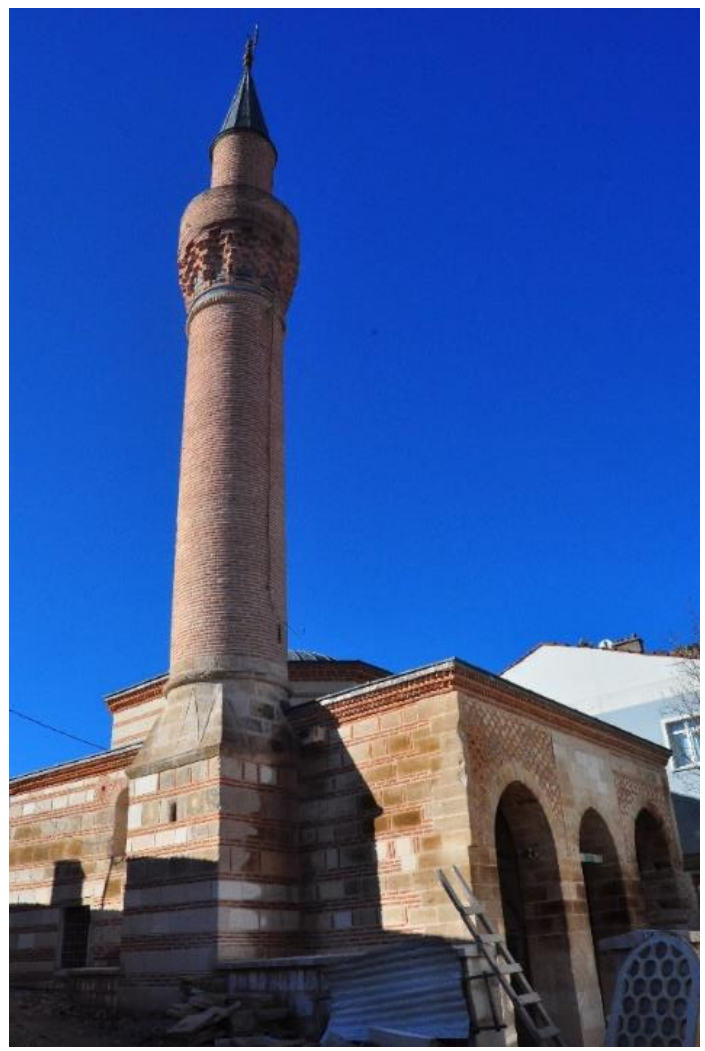

(a) North-East façade

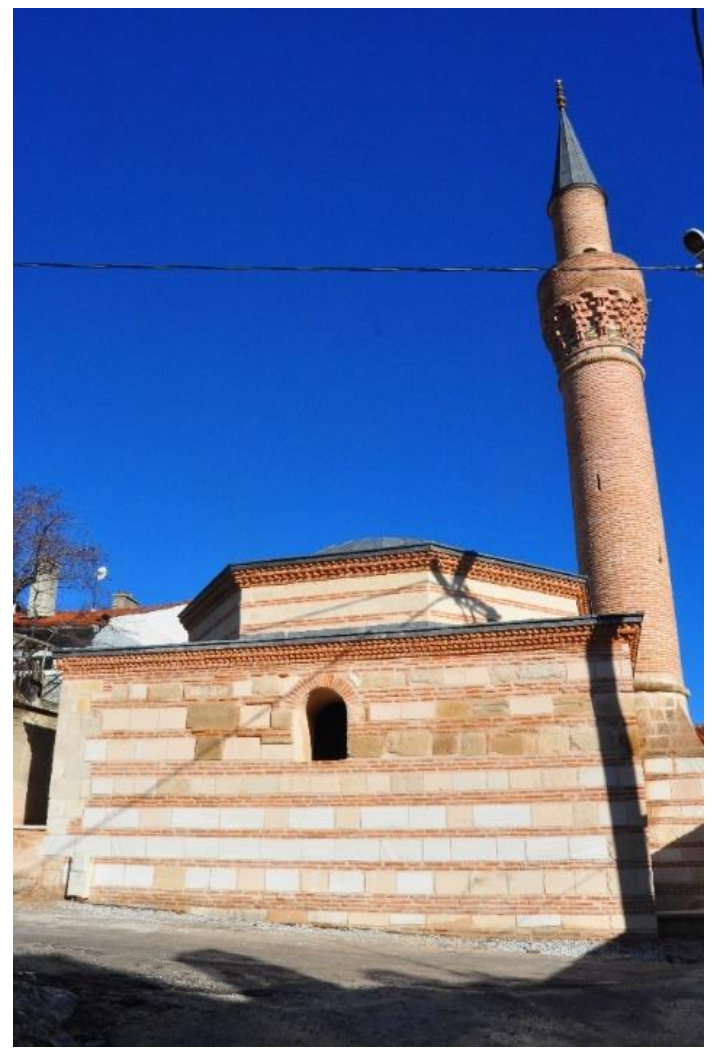

(b) South façade

Figure 2. Kütahya Kurşunlu Mosque 


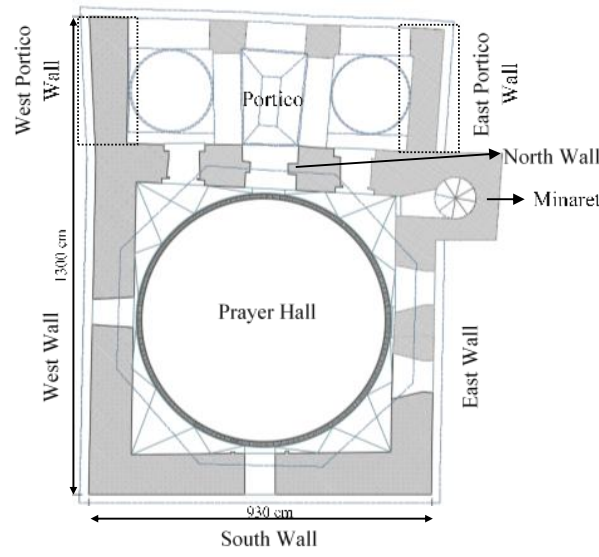

(a) Plan

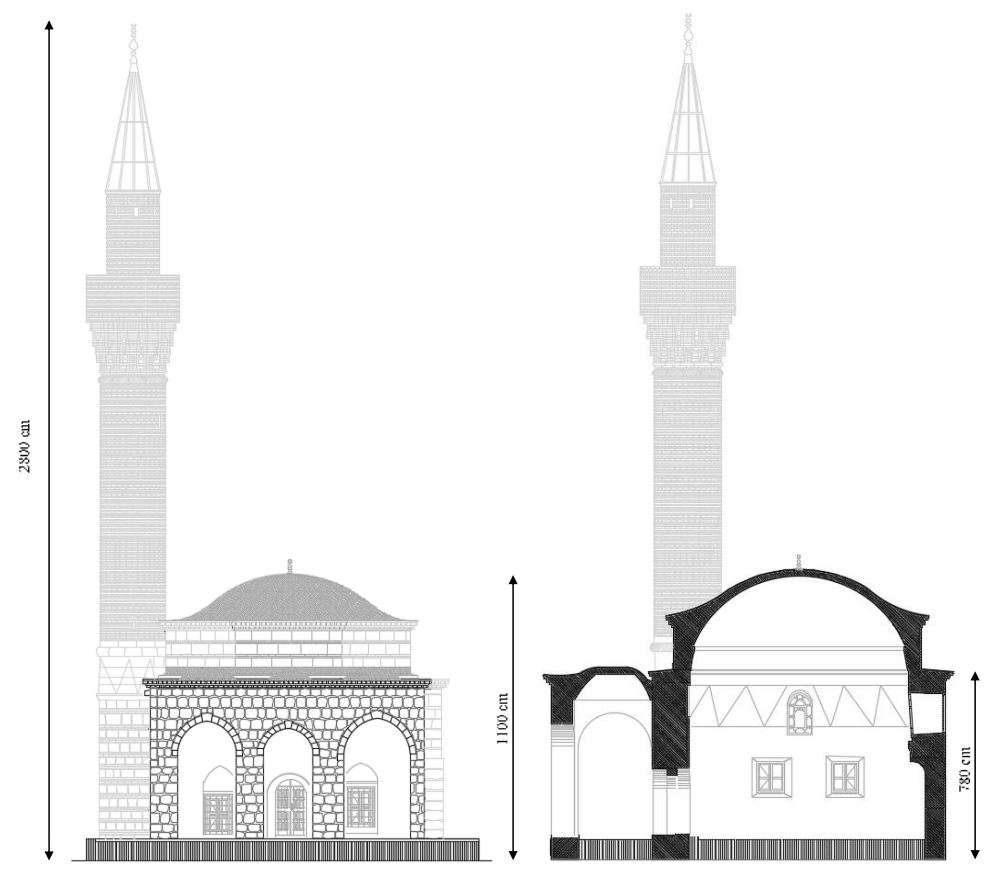

(b) North elevation

(c) East elevation section cut

Figure 3.Geometry of the Mosque

\section{GENERATION OF THE NUMERICAL MODEL}

Different methodologies can be adopted for the seismic assessment of historical masonry structures. Several approaches are available to model and analyze a structure depending on the level of complexity, the time requirement to perform an assessment, the sources that a practitioner has, and financial issues [5]. The Finite Element Method (FEM), which was adopted in the present paper, is the most profound strategy to perform a seismic assessment of existing masonry structures and, therefore, is preferred in the expertise field. However, the adopted methodology has major difficulties in the numerical modeling, particularly for ancient masonry structures, such as the lack of information about the geometry, especially the internal morphology, the sophisticated architectural features, and the variability in mechanical properties of the material and the global structural system [5]. Therefore, a set of certain simplifications is required, and every detail of the structure cannot be considered during the description of the geometry, in which simplified versions of the numerical models are adopted.

In this context, a three-dimensional representative model of the Mosque was prepared by using Midas FX+ for DIANA [6] (Figure 4). The macro-modeling approach, which assumes a homogenous material behavior [7], was adopted. The linear material properties are given in Table 1 . The majority of the structural volume was included in the numerical model, except the minaret, since no structural damage was reported. An optimized numerical model of the Mosque was constituted by beam, shell, and solid elements. Steel girder elements on the retrofitted structural scheme were modeled by a set of beam elements (L13BE). On the other hand, the load-bearing walls, arcades, piers, dome, drum, and pendentives above the portico were numerically modeled by shell elements (T15SH). Due to computational concerns, lintel elements were also defined, as addressed in [8] (see Figure 5). The section properties of the shell elements are provided in Table 2. In fact, the shell elements are present the middle plane of the structural elements and, therefore, simplified arrangements were required. In specific, the structural configuration between the dome, octagonal drum, and load-bearing walls differs 
from the real system due to middle planes assumption of the shell elements (Figure 6(a)-(b)). Moreover, a set of solid elements (tetrahedron TE12L) appeared to be more suitable to model the complex volumetric geometry of the pendentives, as given in Figure 6(c)-(d). Since the internal morphology and variation in the thickness of the dome are unknown, different thickness values, tapered to the top, were defined based on the architectural drawings, in order to have a better representation of the dome component, as presented in Table 2. Besides, it is noted that a constant thickness was defined for the slab above the portico to prevent high deformations due to bending.

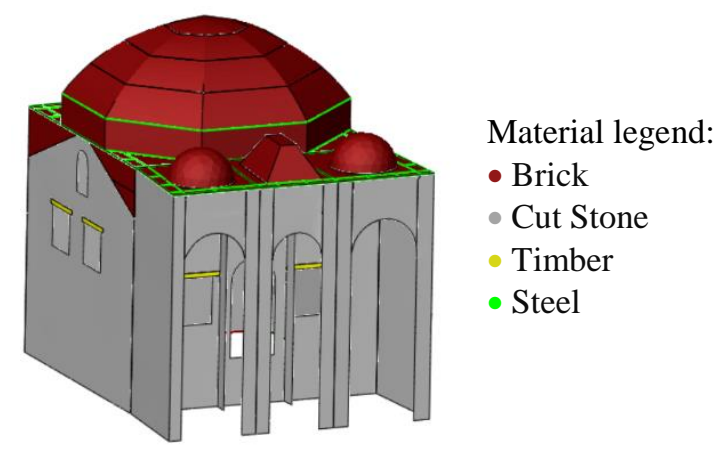

(a) The configuration of the materials

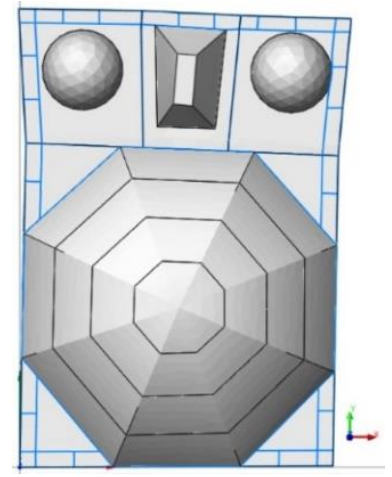

(b) Plan view

Figure 4. Numerical Model of the historical Kütahya Kurşunlu Mosque

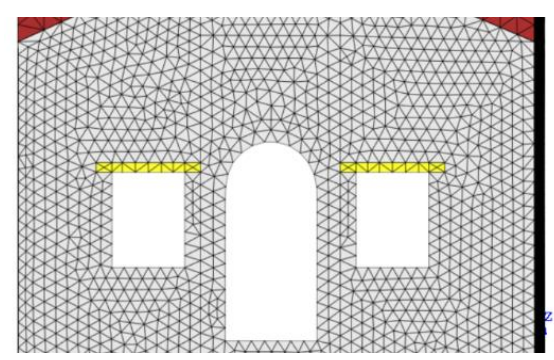

(a) North façade

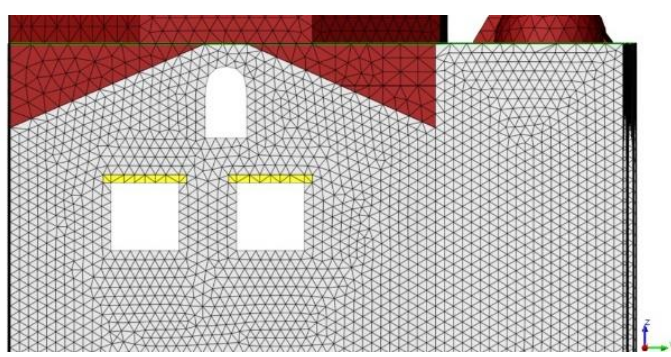

(b) East façade

Figure 5. Elastic lintel elements (colored in yellow)

The adopted triangular mesh size was considered to be $200 \mathrm{~mm}$ for the load-bearing walls and arcades, in order to minimize convergence problems affected by mesh size and mesh distortions during nonlinear analysis, while a coarser mesh size, of $300 \mathrm{~mm}$, was adopted for the dome, drum, pendentives, and vaults. The numerical model of the retrofitted Mosque accounts for 27,250 elements, in which 428 are beam elements, 22,978 are triangular shell elements, and 3,844 are tetrahedral solid elements, with a total of 12,892 nodes and 72,950 degrees of freedom. The degrees of freedom located at the foundation of the structural system were assumed as fully fixed.

\begin{tabular}{cccc}
\hline Material & $\gamma(\mathbf{t} / \mathbf{m} \mathbf{3})$ & $\mathbf{E}(\mathbf{M P a})$ & $\boldsymbol{v}$ (Poisson ratio) \\
\hline Cut Stone & 2.1 & $1500^{*}$ & 0.2 \\
Brick & 2 & $2500^{*}$ & 0.2 \\
Timber & 0.7 & 11000 & 0.3 \\
Steel & 7.85 & 235000 & 0.3 \\
\hline
\end{tabular}

*Calibrated parameters

Table 1. Linear material properties 


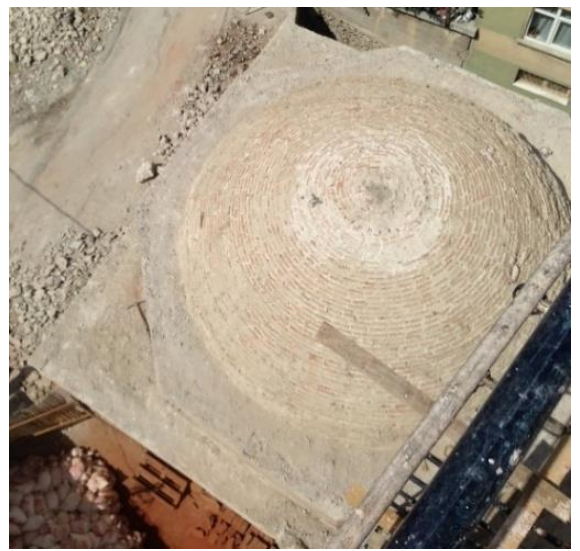

(a) Top view

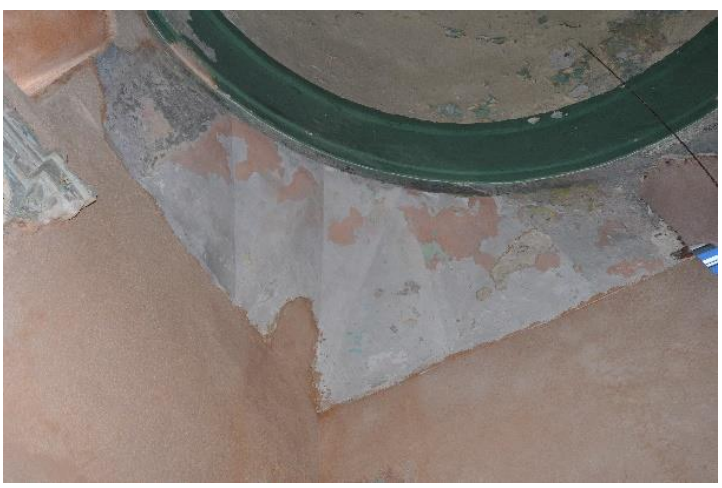

(c) Pendentive

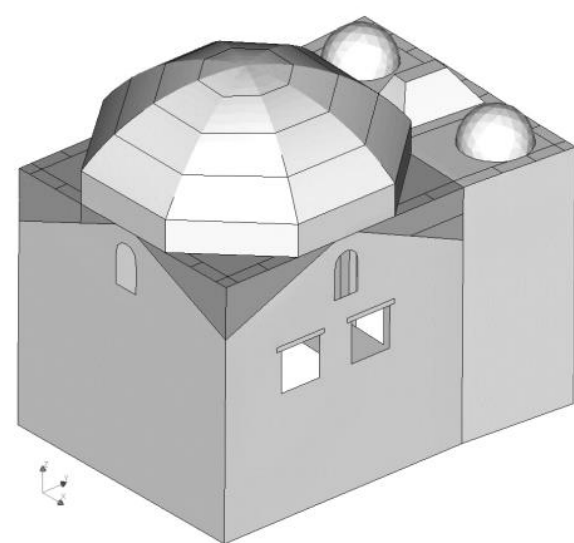

(b) 3D geometry model

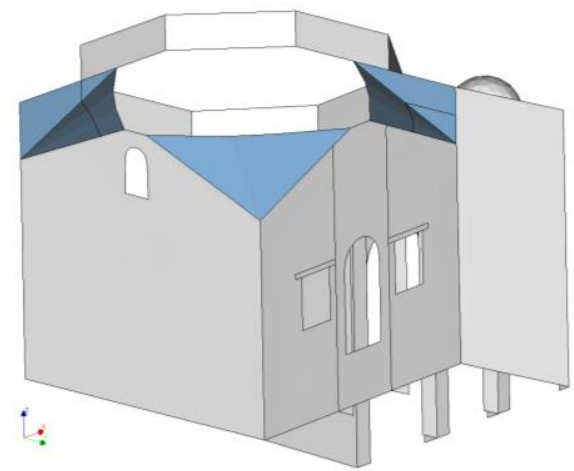

(d) Solid element model of the pendentives, blue colored Figure 6. Adopted geometrical simplifications

\begin{tabular}{ccc}
\hline Elements & Thickness $(\mathbf{m m})$ & Material \\
\hline South wall & 1000 & Cut stone \\
East wall & 1000 & Cut stone \\
West wall & 1000 & Cut stone \\
North wall & 1200 & Cut stone \\
Dome_0.5m & 500 & Brick \\
Dome_0.4m & 400 & Brick \\
Dome_0.3m & 300 & Brick \\
Dome_0.2m & 200 & Brick \\
Drum & 800 & Brick \\
Portico walls & 1000 & Cut Stone \\
Interior west arcade & 700 & Cut Stone \\
Interior east arcade & 700 & Cut Stone \\
Exterior arcades & 800 & Cut Stone \\
Piers & 900 & Cut Stone \\
East Lintel & 1000 & Timber \\
West Lintel & 1200 & Timber \\
Vaults & 200 & Brick \\
Portico Slab & 600 & Brick \\
\hline
\end{tabular}

Table 2. Physical properties of the shell elements 


\section{IDENTIFICATION OF MODAL PARAMETERS}

According to ICOMOS [9], the original configuration of a monumental structure shall be respected, and minimum interventions should be applied. In this respect, structural diagnosis is preferred to be performed in the most non-destructive way in order to identify existing properties and conditions. There are several experimental methods which are used to identify local or global properties of these structures and experimental modal identification tests are one of the most common and effective methods, on a more global basis. Several numerical studies have been carried out by using experimental modal identification tests on the historical structures, and identification of the modal parameters was achieved successfully [10-13].

Dynamic-based modal identification includes numerical and experimental modal analyses, as presented in Figure 7. An ambient vibration test was performed on the Mosque using environmental vibrations as a source of excitation. Following that, an Operational Modal Analysis (OMA) was performed, and experimental modal parameters were extracted using ARTeMIS Modal software [14]. A preliminary eigenvalue analysis was performed, and FEM responses were compared with OMA responses in terms of mode shapes and natural frequencies. The model was improved by using a trial and error approach until the difference between the results, which is defined as "J", was minimized to an acceptable error ratio.

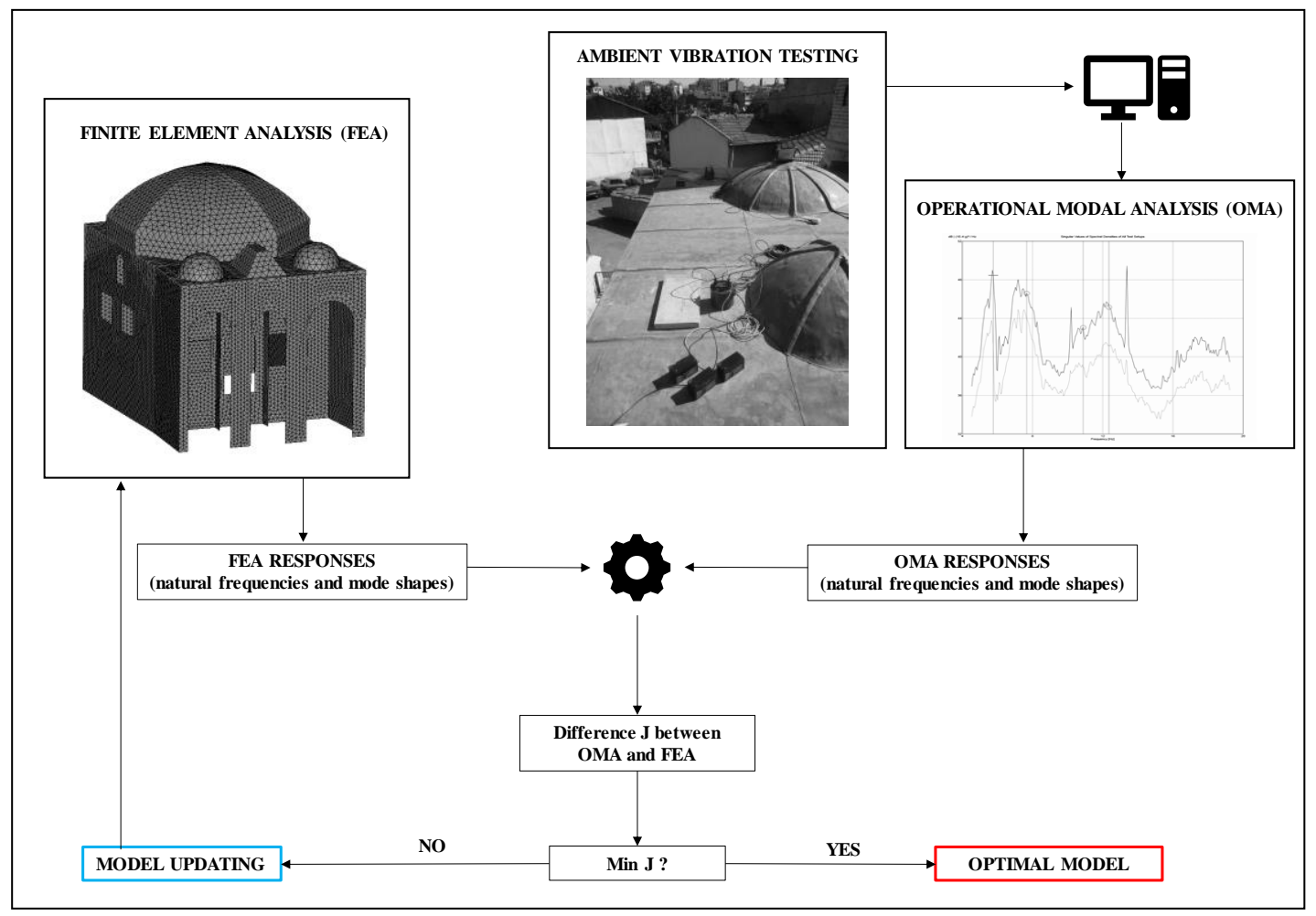

Figure 7. Dynamic-based assessment of the structure, adapted from [10]

\subsection{Ambient Vibration Measurements on the Mosque}

Reference-based ambient vibration measurements were performed due to a limited number of accelerometers. Two digital triaxial accelerometers, which have a frequency range of DC- $100 \mathrm{~Hz}$ with a sensitivity range from \pm 0.1 to $\pm 4.0 \mathrm{~g}$ and $10 \mathrm{~V} / \mathrm{g}$ of resolution, were used. Additionally, a data acquisition system with 24 bits resolution was used for collecting the data. During the measurements, a reference station was fixed on a certain point while another accelerometer was relocated to seven different points on the top of the structural 
walls, as shown in Figure 8. Ambient vibration data were recorded for approximately 20 minutes at each station, whereas the reference station was continuously operated during the measurement. The location of each station on the Mosque was decided based on the modal response of a preliminary numerical model, with respect to identification of the in-plane and out-of-plane movement of the structural components.

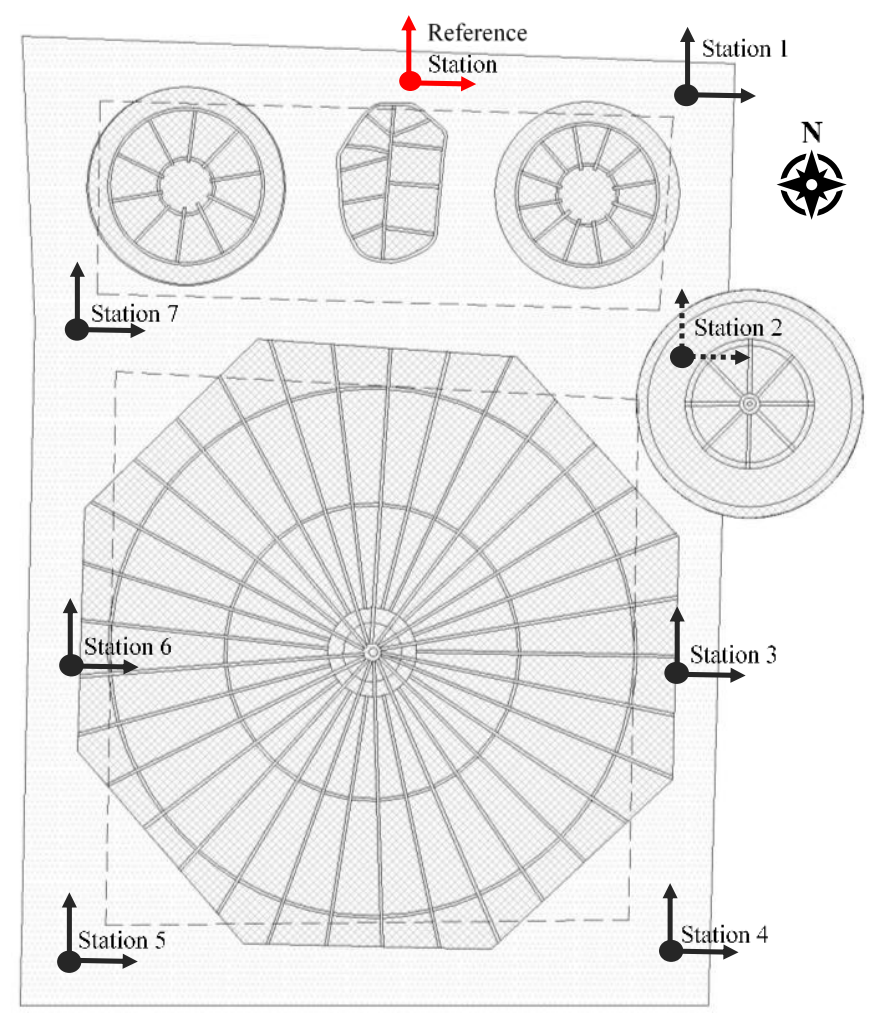

Figure 8. Station layout and sensor directions

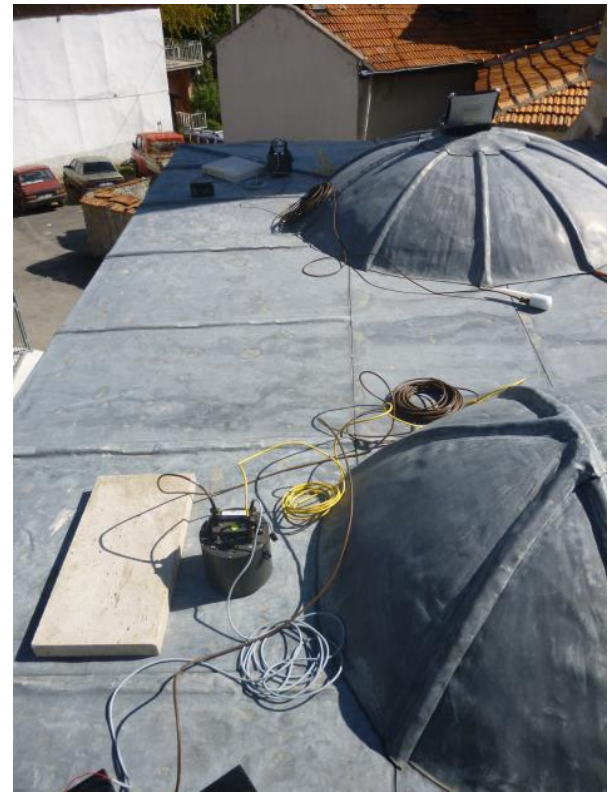

(a) Base and $1^{\text {st }}$ station

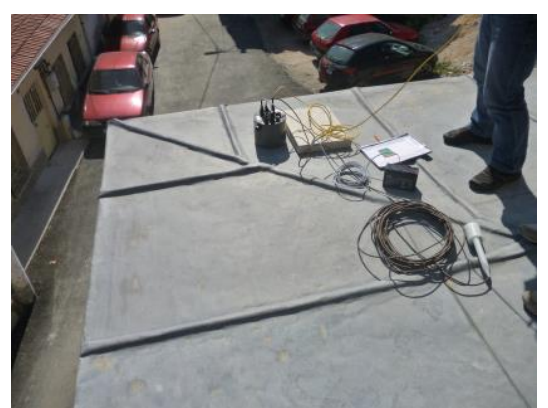

(b) $4^{\text {th }}$ station

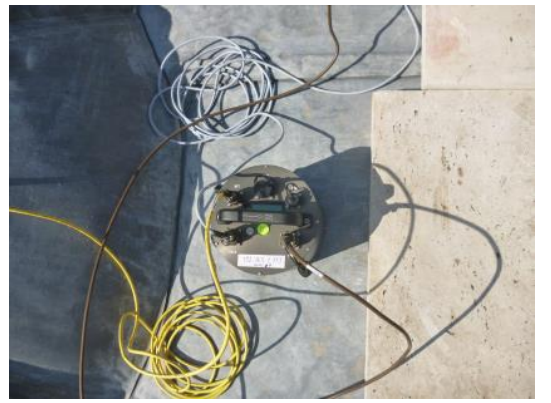

(c) An accelerometer at the base station

Figure 9. Test equipment 


\subsection{Operational Modal Analysis}

In the present paper, OMA was carried out by using two different signal processing methodologies, namely the Enhanced Frequency Domain Decomposition (EFDD) and the Unweighted Principal Components-Stochastic Subspace Identification (SSI-UPC) methods, and the comparison of the two was performed in terms of Modal Assurance Criterion (MAC). Aguilar et al. addressed that the reliability of the results mainly depends on the environmental noise, structural components, quality of measurement of the system and technical expertise from the experimental campaign personnel [12]. The EFDD is a non-parametric method, which is mostly developed in the frequency domain, while the SSI is defined as a parametric method, originated in the time domain. Still, both methods can be used, however, the results of the non-parametric methods are mainly influenced by the quality of the environmental noise, and this drawback can be overcome by using parametric methods [15].

The analyses performed using the EFDD and SSI methods are shown for the first four modes of vibrations in Figure 10 and Figure 11, respectively. The EFDD method resulted in several sharp peaks within the range of $4 \mathrm{~Hz}-15 \mathrm{~Hz}$. However, the selected modes of vibrations marked by circles (see Figure 10) do not correspond to the peak ones. The main reason is that the results obtained from the peaks appear to be local vibrations and, therefore, the influence of the undesired source of vibrations might be included. On the other hand, the identification of the modes of vibrations was conducted by the selection of the stable pole columns and linkage of setups with each other. The selection process of the poles was mainly based on the frequency values and mode shapes. Calculated MAC values obtained from both methods are presented in Table 3. In the present paper, the latter was considered to be as the experimental modal response of the historical mosque.

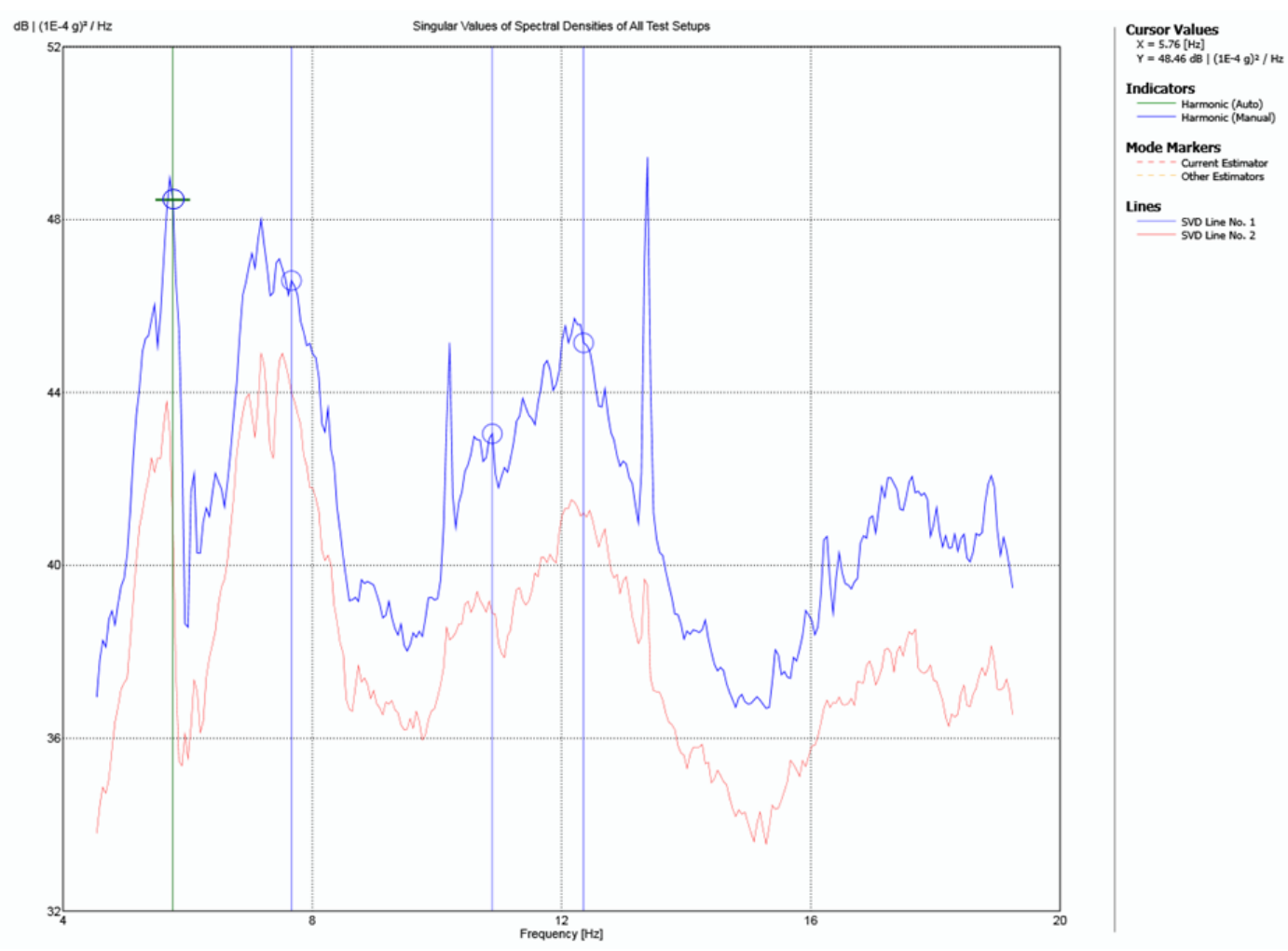

Figure 10. The EFDD method, with singular values of spectral densities of all setups 


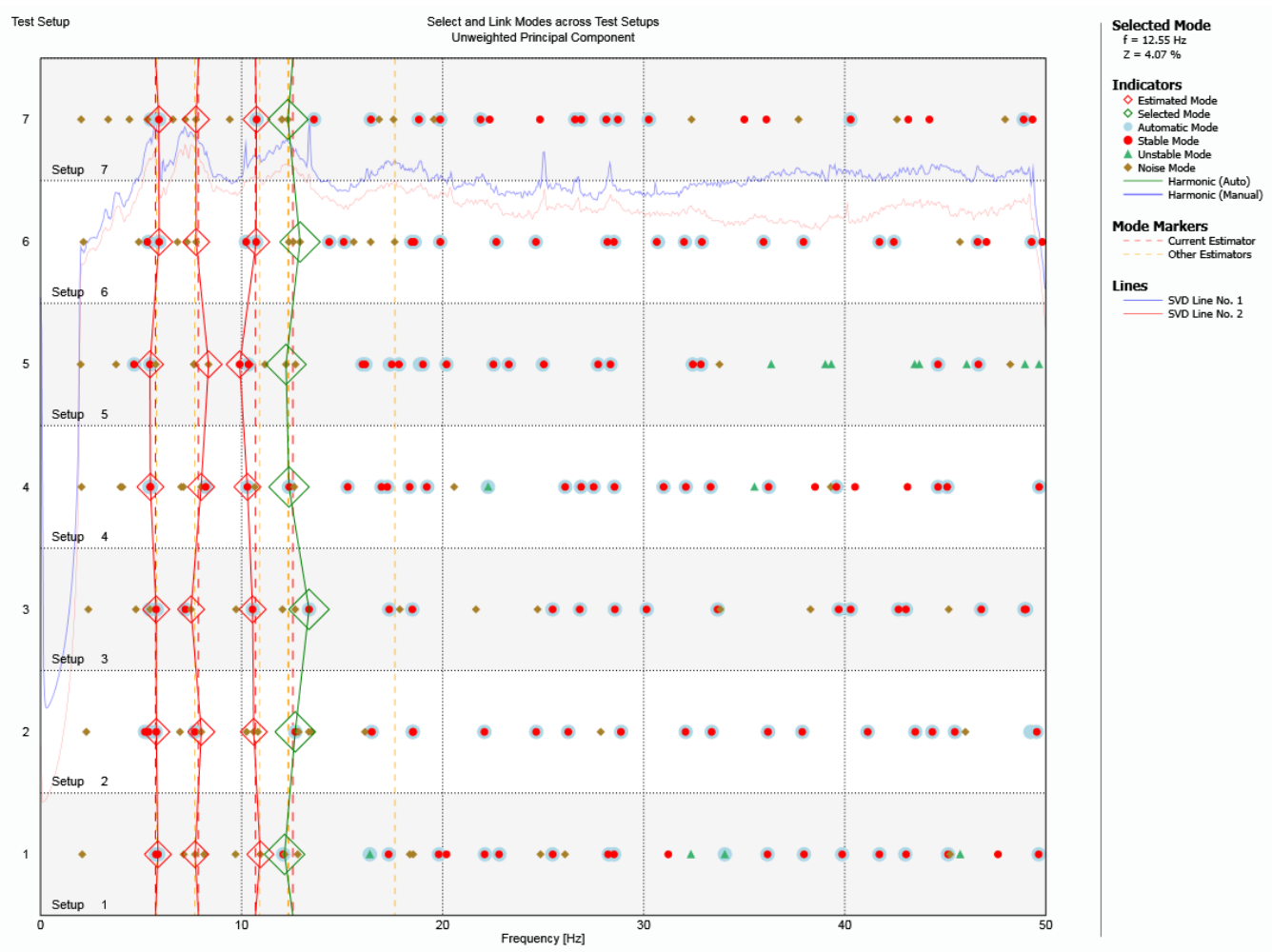

Figure 11. The SSI-UPC method, with selection and linking process of modes across all test setups

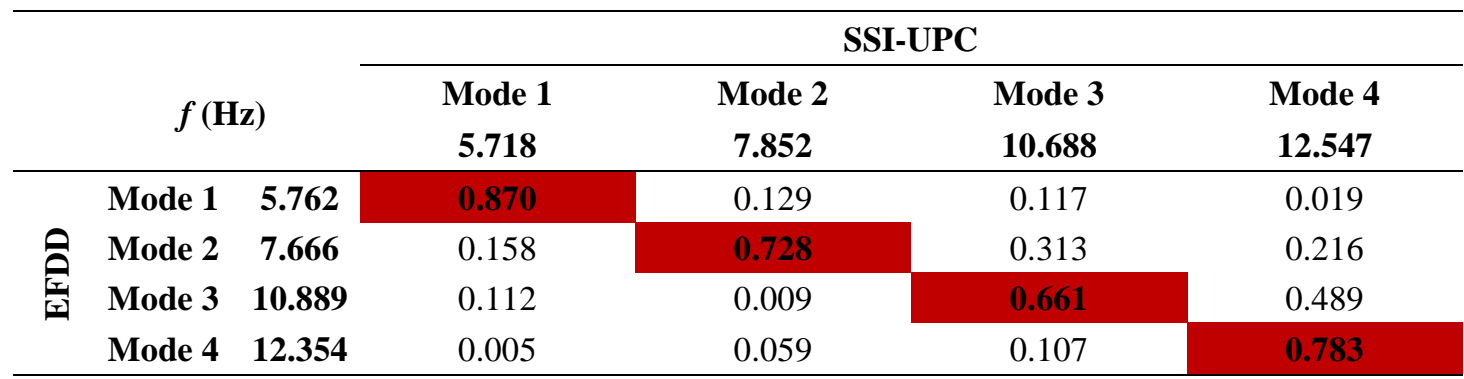

Table 3. Comparison between the SSI-UPC and the EFDD results in terms of MAC

\section{CALIBRATION OF THE NUMERICAL MODEL AND EIGENVALUE ANALYSIS}

Once the OMA only allows the identification of the elastic structural behavior of the Mosque, the elastic stiffness of the structure was calibrated, whereas the modulus of elasticity of the masonry materials, namely cut stone and brick masonry, was considered to be the variable parameter in the calibration process. The numerical calibration was performed over the retrofitted model and was achieved by fitting the obtained numerical eigenvalues with the experimental ones, through a trial and error approach. The comparison is given in Table 4 in terms of MAC values, numerical and experimental frequencies, and their relative differences. It is important to note that higher MAC values, generally greater than 0.8 and not lower than 0.4 , are desired for each mode shape [10]. However, the calibration process was based on the minimization of the difference in the frequency content. In fact, the MAC values obtained for the second and third modes presented poor correlation. Still, the calibration of the model was achieved by having an average error of $4.9 \%$ of the first four frequencies (Table 4). Finally, the calibrated Young's modulus was found to be $1500 \mathrm{MPa}$ and $2500 \mathrm{MPa}$ for cut stone and brick, 
respectively. The mode shapes of the experimental and numerical analyses are given in Figure 12.

\begin{tabular}{cccccc}
\hline Mode & $\boldsymbol{f}_{\boldsymbol{e x p}}(\mathbf{H z})$ & $\boldsymbol{f}_{\text {num }}(\mathbf{H z})$ & Error $(\boldsymbol{\%})$ & Average Error $(\%)$ & MAC \\
\hline 1 & 5.72 & 5.77 & 0.9 & & 0.75 \\
2 & 7.85 & 7.87 & 0.2 & 4.9 & 0.40 \\
3 & 10.69 & 9.77 & 8.6 & & 0.51 \\
4 & 12.55 & 11.32 & 9.8 & 0.85 \\
\hline
\end{tabular}

Table 4. Comparison of the experimental and calibrated numerical results

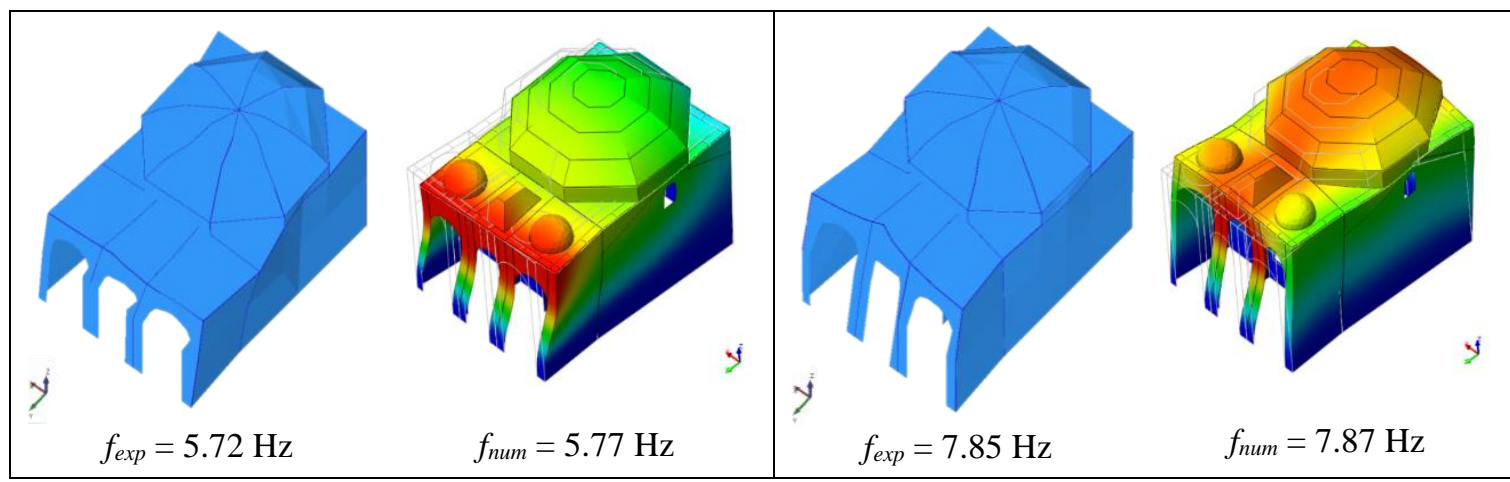

(a) $1^{\text {st }}$ mode

(b) $2^{\text {nd }}$ mode

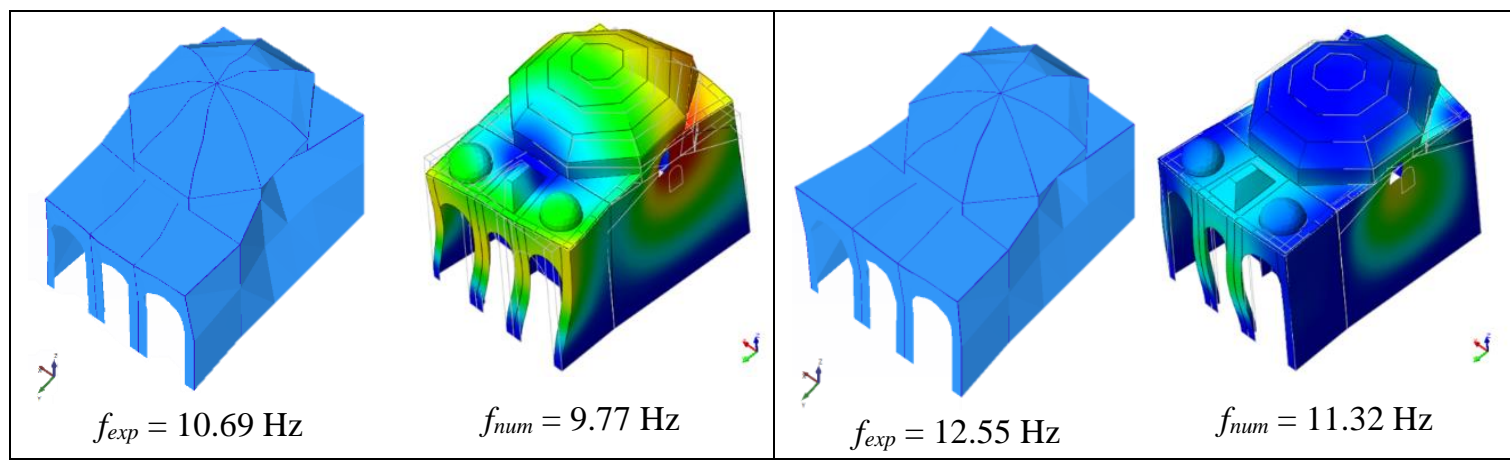

(c) $3^{\text {rd }}$ mode

(d) $4^{\text {th }}$ mode

Figure 12. Experimental and calibrated numerical modes of vibrations

Accordingly, it can be concluded that the first four modes obtained from the calibrated numerical model characterize the dynamic behavior of the mosque sufficiently with nearly $70 \%$ of mass participation in $\mathrm{x}$ and y-direction. As indicated in [16], the first few modes provide accurate results for such N-DOF system. The global frequencies range from $5.77 \mathrm{~Hz}$ to $11.32 \mathrm{~Hz}$ for the first four mode shapes whereas the cumulative mass participation ratio was found to be $70.83 \%$ and $67.28 \%$ in the $\mathrm{x}$ (transversal) and $\mathrm{y}$ (longitudinal) direction, respectively (Table 5). 


\begin{tabular}{cccccc}
\hline \multirow{2}{*}{ Mode } & $\boldsymbol{f}(\mathbf{H z})$ & Period (s) & \multicolumn{3}{c}{ Cumulative Mass Participation (\%) } \\
& & & $\mathbf{X}$ component & Y component & Z component \\
\hline 1 & 5.78 & 0.17 & 60.72 & $\approx 0.00$ & $\approx 0.00$ \\
2 & 7.87 & 0.13 & 61.13 & 66.95 & $\approx 0.00$ \\
3 & 9.77 & 0.10 & 70.80 & 67.27 & $\approx 0.00$ \\
4 & 11.32 & 0.09 & 70.83 & 67.28 & $\approx 0.00$ \\
100 & 59.32 & 0.02 & 90.35 & 89.84 & 82.69 \\
\hline
\end{tabular}

Table 5. Modal response of the numerical model for the first 100 modes in each direction

\section{CONCLUSIONS}

Numerical modeling and experimental modal identification of the historical Kütahya Kurşunlu Mosque is presented in the current paper. Firstly, a finite element model of the Mosque was prepared by taking account several strategies, such as a simplified geometry, the non-consideration of the minaret, and specifically, an adaptation of the macro-modeling approach. It is noted that a preliminary eigenvalue analysis is useful to find out proper locations for the sensors which are to be used for the ambient vibration tests. The referencebased ambient vibration test provided sufficient data to obtain the global modal response of the real structure. However, the OMA results show that undesired sources of vibration have influenced the data obtained, regardless of the methodology adopted for identification. Eventually, second and third modes of vibration show poor correlation, while the first and fourth mode shapes give reliable results in terms of MAC. Even so, the calibration approach based on the error minimization of the frequency values, between the operational and eigenvalue analyses, is considered reliable enough, since the mass participation ratio of the first mode is nearly $61 \%$, which is more than expected in these particular structures. Therefore, an average error of $4.9 \%$ in the frequency for the first four modes is considered to be acceptable. Once the OMA only concluded on estimating the elastic stiffness of the structure, the calibration of the numerical model was adopted for the structural material masonry in the present case- in the linear range.

\section{REFERENCES}

[1] Jokilehto, J. A History of Architectural Conservation. Butterworth-Heinemann. 1999.

[2] Roca, P. "The study and restoration of historical structures: From principles to practice". In P. B. Lourenço, P. Roca, C. Modena, \& S. Agrawal (Eds.), Structural Analysis of Historical Constructions (pp. 9-24). New Delhi. 2006.

[3] Lourenço, P. B., Mendes, N., Ramos, L. F., Oliveira, D. V. "Analysis of masonry structures without box behavior". International Journal of Architectural Heritage, 5(45), pp. 369-382. 2011. DOI:10.1080/15583058.2010.528824

[4] AFAD. "Earthquake Hazard Map of Turkey". 2018. Retrieved from https://tdth.afad.gov.tr/

[5] Lourenço, P. B. "Analysis of historical constructions: From thrust-lines to advanced 
simulations". In P. B. Lourenço \& P. Roca (Eds.), Historical Constructions (pp. 91116). Guimaraes. 2001.

[6] FX+ for DIANA. "Midas FX+ for DIANA, Customized Pre/Post-processor for DIANA". MIDAS Information Technology Co., Ltd. 2013.

[7] Lourenço, P. B. "Computations on historic masonry structures". Progress in Structural Engineering and Materials, 4(3), pp. 301-319. 2002. DOI:10.1002/pse.120

[8] Lourenço, P. B., Krakowiak, K. J., Fernandes, F. M., Ramos, L. F. "Failure analysis of Monastery of Jerónimos, Lisbon: How to learn from sophisticated numerical models". Engineering Failure Analysis, 14(2), pp. 280-300. 2007. DOI:10.1016/j.engfailanal.2006.02.002

[9] ICOMOS. "ICOMOS Turkey Architectural Heritage Conservation Charter". 2013. Retrieved from http://www.icomos.org.tr/Dosyalar/ICOMOSTR_0623153001387886624.pdf

[10] Gentile, C., Saisi, A. "Ambient vibration testing of historic masonry towers for structural identification and damage assessment". Construction and Building Materials, 21(6), pp. 1311-1321. 2007.

[11] Sevim, B., Bayraktar, A., Altunişik, A. C., Atamtürktür, S., Birinci, F. "Assessment of nonlinear seismic performance of a restored historical arch bridge using ambient vibrations". Nonlinear Dynamics, 63(4), pp. 755-770. 2011.

[12] Aguilar, R., Torrealva, D., Ramos, L. F., Lourenço, P. B. "Operational Modal Analysis Tests on Peruvian Historical Buildings: The Case Study of the 19 th Century Hotel Comercio". In 15th World Conference on Earthquake Engineering, Lisbon Portugal. 2012.

[13] Nohutcu, H., Demir, A., Ercan, E., Hokelekli, E., Altintas, G. "Investigation of a historic masonry structure by numerical and operational modal analyses". The Structural Design of Tall and Special Buildings, (24), pp. 821-834. 2015.

[14] ARTeMIS Modal. "SVS-Structural Vibration Solutions A/S". Denmark. (n.d.)

[15] Ramos, L. F., Aguilar, R., Lourenço, P. B. "Operational modal analysis of historical constructions using commercial wireless platforms". Structural Health Monitoring, 10(5), pp. 511-521. 2010.

[16] Chopra, A. K. Dynamics of Structures: Theory and Application to Earthquake Engineering (fourth.). Printince Hall. 2012. 